\title{
A Novel Protection and Location Scheme for Pole-to-Pole Fault in MMC-MVDC Distribution Grid
}

\author{
Yu Zeng ${ }^{1}$, Guibin Zou ${ }^{1, *} \mathbb{D}$, Xiuyan Wei ${ }^{1}$, Chenjun Sun ${ }^{2}$ and Lingtong Jiang ${ }^{1}$ \\ 1 Key Laboratory of Power System Intelligent Dispatch and Control of Ministry of Education, Shandong \\ University, Jinan 250061, China; zengyu@mail.sdu.edu.cn (Y.Z.); weixiuyan@sdu.edu.cn (X.W.); \\ jianglingtong@mail.sdu.edu.cn (L.J.) \\ 2 State Grid Hebei Electric Power Corporation, Shijiazhuang 050021, China; scj@he.sgcc.com.cn \\ * Correspondence: guibinzou@sdu.edu.cn; Tel.: +86-135-0541-6354
}

Received: 9 July 2018; Accepted: 7 August 2018; Published: 9 August 2018

\begin{abstract}
Nowadays, the efficient and reliable protection and location schemes for MMC-MVDC (Modular Multilevel Converter-Medium Voltage Direct Current) grid are few. This paper is the first to propose a scheme to not only protect the feeders and the busbar, but locate the segments in MMC-MVDC grid. To improve the reliability, this paper analyzes the transient characteristics of the pole-to-pole fault and then obtains the characteristic frequency band. Based on S-transform, STCFB (S-transform characteristic frequency band) Phase of fault component is utilized to construct the identification criterion for faulty feeder and faulty segment. The whole scheme can be divided into three steps, namely, protection starting criterion, faulty feeder and busbar protection criterion, and faulty segment location criterion. Firstly, the current gradient method is utilized to quickly detect the fault and start the protection device. Secondly, the non-unit protection criterion on busbar and feeders is proposed according to STCFB Phase of the voltage and current fault component. Thirdly, according to the STCFB Phase on both sides of the feeder segment, the faulty segment can be located. A radial MMC-MVDC distribution network model was built in PSCAD/EMTDC software to evaluate the performance of the protection and location method. Simulation results for different cases demonstrate that the proposed scheme has high accuracy, good adaptability and reliability.
\end{abstract}

Keywords: MMC-MVDC; non-unit protection; segment location; STCFB Phase

\section{Introduction}

With the development of modern power electronics technology and the increase of new energy power generation systems, the Medium Voltage Direct Current (MVDC) distribution grid will have a good prospect [1-4]. A Modular Multilevel Converter (MMC) usually has a large number of sub-modules [5]. To improve the quality of converter output waveform, nearest level modulation (NLM) method has been widely adopted [6]. Compared with two-level and three-level voltage source converters (VSCs), MMC has higher reliability and lower switching frequency $[7,8]$. Thus, MMC-MVDC has been favored in flexible DC projects such as $\pm 10 \mathrm{kV}$ hand-in-hand China Southern Power Grid [9].

As one of the key technologies of flexible DC distribution grid, the protection schemes of MMC-MVDC are still not mature [10]. Due to the huge differences of operation modes and fault characteristics, the protection methods of the AC system cannot be directly implemented to the MMC-MVDC distribution grid [11]. On the other hand, due to the relatively small values of resistance and inductance in DC cables, the rise rate of fault current is very high and DC circuit breakers are yet to be commercially available [12]. In order to prevent the Insulated Gate Bipolar Transistors (IGBTs) 
of MMC from losing controllability [13], the protection system should fast identify and isolate the faulty lines.

Traveling wave (TW)-based protection schemes satisfy the high-speed requirements in detecting and locating the faults in High Voltage Direct Current (HVDC) grid [14-16], but they are vulnerable to the fault resistances. Moreover, TW-based schemes need a relatively high sampling rate in distribution grid. Fault detection method using overcurrent have been proposed [17,18], but it is difficult to discriminate the faulty area and the adjacent normal areas. In addition, these methods require data synchronization. Distance protection based on the fault equivalent circuit and Kirchhoff law has been proposed for fault detection and location [19], however the calculation error and uncertainty of the transition resistance will have an impact on the calculation result due to the short length of the feeder.

The handshaking method proposed in Reference [20] identifies and isolates fault by comparing the initial current change, the current rise time interval and the current oscillation pattern at different switch locations. Nevertheless, this algorithm is a bit slow and will lead to prolonged shut down of the complete system. As multi-level segments in MMC-MVDC have no clear boundaries between each other, the schemes based on the harmonic current [21] cannot identify the faulty segment in the multi-branch distribution grid. To locate the fault and avoid the use of telecommunication, the relationship between DC-link voltage and fault distance is derived in Reference [22]. However, this method cannot give an accurate indication of the fault location. Moreover, the algorithm requires solid-state or fast hybrid D circuit breakers (DCCBs) to clear the fault. In Reference [23], the derivative of DC voltage is proposed to quickly detect and locate DC faults in a bipolar HVDC grid. However, the switching load will bring interference to the protection controller, resulting in the maloperation of the protection.

It is apparent that the schemes above mainly focus on Low Voltage Direct Current (LVDC) grids and HVDC grids. The comprehensive protection and location schemes in MMC-MVDC grid are seldom proposed. Thus, this paper is the first to propose a scheme to protect the faulty feeder and busbar, and locate the faulty segment simultaneously in MMC-MVDC distribution grid. In addition, this paper firstly analyzes the characteristic frequency band of MMC and fault component of DC cables to improve the reliability; the last but not the least important, this paper firstly utilizes S-transform in MMC-MVDC distribution grid.

The remainder of the paper can be structured as follows. Firstly, radial MMC-MVDC distribution grid topology is introduced in Section 2; and the fault characteristics and characteristic frequency band are analyzed in detail. Then, in order to extract characteristic frequency band, Section 3 introduces $S$ transform and its related theory; and S-transform characteristic frequency band (STCFB) and STCFB Phase is defined. In Section 4, the protection starting scheme based on current gradient method is firstly introduced; then secondly, the faulty feeder can be selected, utilizing STCFB Phase of the fault component at the beginning of the feeder; and thirdly, the faulty segment can be located by STCFB Phase of the current fault component on both sides of the segment. Section 5 verifies the reliability and accuracy of the proposed algorithm by a large number of simulations in PSCAD/EMTDC. Finally, Section 6 summarizes the full text and draws the conclusion.

\section{Fault Analysis of DC Distribution Grid}

\subsection{Radial MMC-MVDC Distribution Grid Topology}

Compared with hand-in-hand and ring topologies, the radial DC distribution grid is widely adopted due to low investment. As shown in Figure 1, the system is composed by single MMC station which works in DC voltage control. 0.25 MW PV plant is boosted via a DC/DC converter into a $\pm 10 \mathrm{kV}$ DC busbar. The system parameters are shown in Table 1 and the parameters of DC cable are shown in Table 2. 


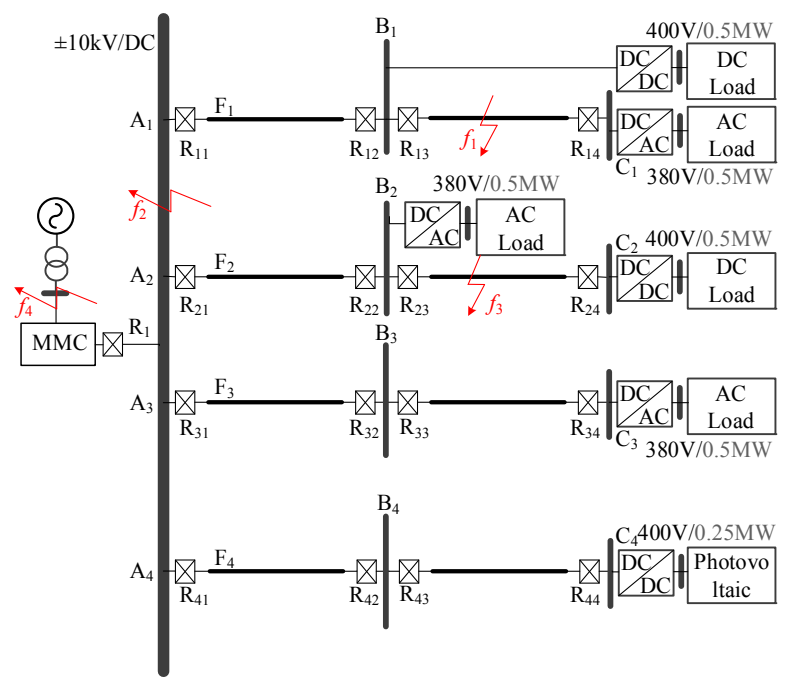

Figure 1. Radial Modular Multilevel Converter-Medium Voltage Direct Current (MMC-MVDC) distribution grid topology.

Table 1. System parameters.

\begin{tabular}{cc}
\hline Parameters & Value \\
\hline Voltage of AC system & $110 \mathrm{kV}$ \\
AC side rated voltage of MMC & $10 \mathrm{kV}$ \\
Rated active power of MMC & $5 \mathrm{MW}$ \\
Rated active power of photovoltaic & $0.25 \mathrm{MW}$ \\
Levels of converters & 21 \\
Capacitance of MMC & $5000 \mu \mathrm{F}$ \\
Inductance of bridge & $5 \mathrm{mH}$ \\
\hline
\end{tabular}

Table 2. Parameters of feeder.

\begin{tabular}{cc}
\hline Parameters & Value \\
\hline Resistance & $0.125 \Omega / \mathrm{km}$ \\
Inductance & $0.72 \mathrm{mH} / \mathrm{km}$ \\
Capacitance to ground & $0.0048 \mu \mathrm{F} / \mathrm{km}$ \\
AmBm, BmCm $(\mathrm{m}=1,2,3,4)$ & $10 \mathrm{~km}$ \\
\hline
\end{tabular}

\subsection{Transient Analysis of DC Feeders}

As a MMC-MVDC grid mostly utilizes the small current grounding modes [24], the voltage between two poles remains normal; thus, the system can still operate normally for a period of time. However, when a pole-to-pole fault occurs, the fault current rises rapidly and will bring the most serious hazard to the system. Therefore, this paper proposes the protection scheme mainly focusing on pole-to-pole fault. For a pole-to-pole fault occurring at $f_{1}$ in Figure 1 , the frequency-domain fault superposition circuit schematic of the faulty feeder $F_{1}$ is shown in Figure 2. 


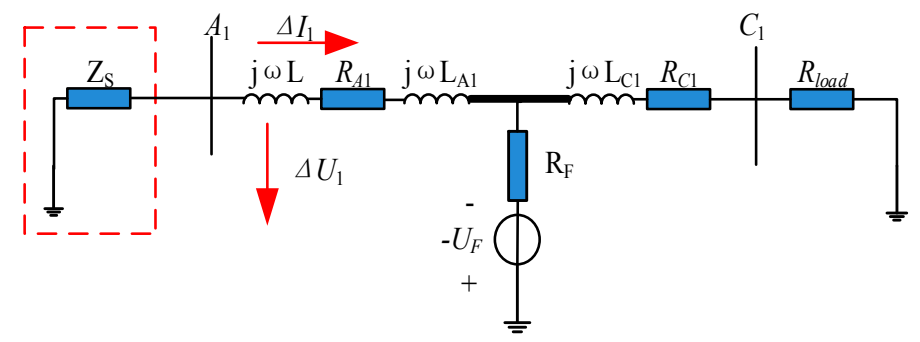

Figure 2. Frequency-domain fault superposition circuit of faulty feeder.

Where, $U_{F}$ represents the fault superimposed voltage source; $Z_{S}$ represents the equivalent impedance of MMC; $\left\{\Delta U_{1}, \Delta I_{1}\right\}$ represent the voltage fault component and the current fault component of the faulty feeder $\left(\mathrm{F}_{1}\right)$ at frequency $\omega$; $R_{\text {load }}$ is the equivalent load impedance; $L$ is the current-limiting reactor installed at the beginning of the feeder; $R_{A 1}, L_{A 1}, R_{C 1}$, and $L_{C 1}$ are the equivalent resistances and inductances on both $A_{1}$ and $C_{1}$ sides, respectively. According to Figure 2, for a faulty feeder, when a pole-to-pole fault occurs on $\mathrm{F}_{1}$, the voltage fault component and current fault component of faulty feeder meet the following relationship:

$$
\frac{\Delta U_{1}}{\Delta I_{1}}=-Z_{S}
$$

While for the normal feeders, the frequency-domain fault superposition circuit can be obtained according to the superposition principle as shown in Figure 3.

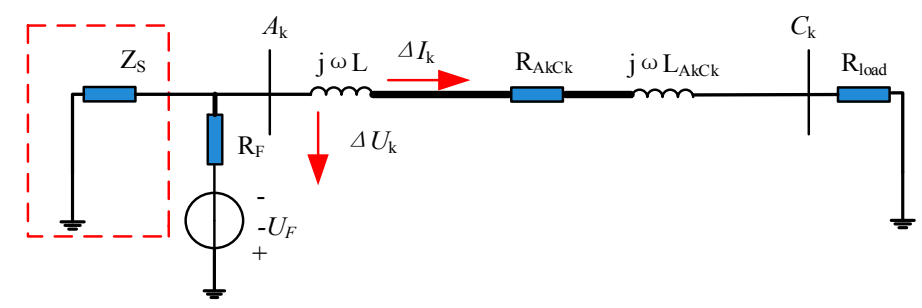

Figure 3. Frequency-domain fault superposition circuit of normal feeders.

From Figure 3, it can be seen that the voltage fault component and current fault component of the normal feeders at the protection installation satisfy the following relationship:

$$
\frac{\Delta U_{k}}{\Delta I_{k}}=j \omega L+R_{A k C k}+j \omega L_{A k C k}+R_{\text {load }}
$$

where, $k=2,3,4$, represents the feeder $\mathrm{F}_{2}, \mathrm{~F}_{3}, \mathrm{~F}_{4} ;\left\{\Delta U_{k}, \Delta I_{k}\right\}$ represent the voltage fault component and the current fault component of the normal feeder $\left(\mathrm{F}_{k}\right)$ at frequency $\omega ; R_{A k C k}, L_{A k C k}$ are equivalent resistances and inductances of the feeder $A_{k} C_{k}$, respectively. According to Equation (2), the phase difference of the voltage fault component and current fault component of the normal feeder should be between $0 \sim 90^{\circ}$.

However, the phase of $Z_{S}$ cannot be directly determined. To solve this problem, the equivalent circuit of $Z_{S}$ is constructed as shown in Figure 4. At this time, MMC is only paralleled by three phase units. 


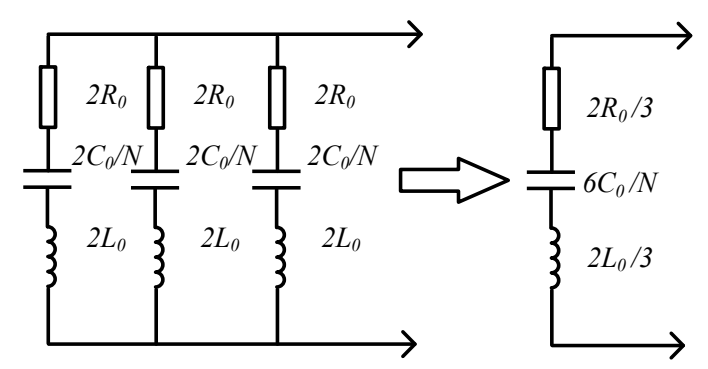

Figure 4. Equivalent Circuit of Pole-to-Pole Fault on MMC

Where, $L_{0}, C_{0}$ represent the bridge reactance and submodule capacitors of MMC; $R_{0}$ is the equivalent resistance of the bridge arm; $N$ is the number of submodules of bridge arm. To analyze the phase of $Z_{S}$, defining the equivalent impedance $Z_{C}$ of the equivalent inductor and the equivalent capacitor as follows:

$$
Z_{C}=j\left(\frac{2}{3} \omega L_{0}-\frac{N}{6 \omega C_{0}}\right)
$$

Thus, the resonant frequency of the circuit is:

$$
f_{\text {res }}=\frac{1}{4 \pi} \sqrt{\frac{N}{L_{0} C_{0}}}
$$

According to Equation (4), when $f>f_{\text {res }}, Z_{C}>0, Z_{S}$ is inductive. According to Table $1, f>f_{\text {res }}=$ $71.2 \mathrm{~Hz}$. That is, when $f>71.2 \mathrm{~Hz}$, the phase difference of voltage fault component and the current fault component of faulty feeder is between $180^{\circ} \sim 270^{\circ}$.

\subsection{Transient Analysis of Feeder Segment}

(1) Internal fault of feeder segment: Take the fault at $f_{1}$ in Figure 1 as an example, when the internal fault occurs at $f_{1}$ for the segment $B_{1} C_{1}$, the superimposed circuit is illustrated as Figure 5 . Assume the positive current direction is from busbar to the line for convenience. According to superposition principle, a negative voltage source $\Delta U_{F}$ is equivalent to be added at the fault point.

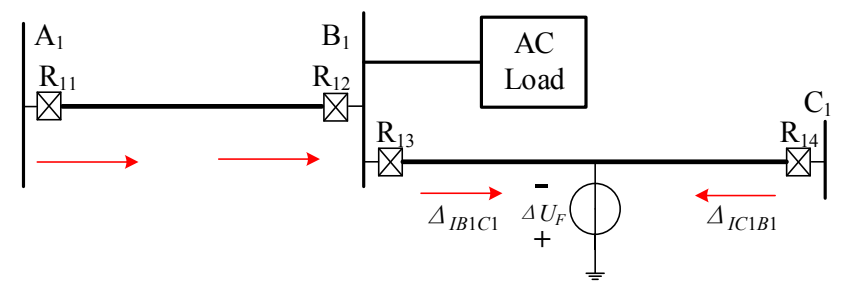

Figure 5. Frequency-domain fault superposition circuit for an internal fault.

Where, $\Delta_{\mathrm{IB} 1 \mathrm{C} 1}, \Delta_{\mathrm{IC1B} 1}$ respectively represent current fault components on both sides of segment $B_{1} C_{1}$. The load is generally connected to the $D C$ busbar via a charging capacitor in the converters. Therefore, when the fault occurs at $\mathrm{f}_{1}$, both sides feed current to the fault point. According to the specified positive direction, the current fault component detected by $R_{13}$ and $R_{14}$ should have the same polarity.

(2) External fault of feeder segment: As there is no boundary between the segments of the same feeder, the current is almost not blocked from propagating between segment $A_{1} B_{1}$ and segment $B_{1} C_{1}$. Therefore, the polarities of the current fault component of the normal feeder detected by $\mathrm{R}_{11}$ and $\mathrm{R}_{12}$ are opposite. 


\subsection{Transient Analysis of Fault on the Bus}

Specify the positive current direction is from the busbar to the line. When a pole-to-pole fault occurs on the DC busbar, the transient current characteristics can be illustrated as Figure 6 . According to the analysis above, the voltage fault component and current fault component detected by the protection installation of feeder $i$ and the converter satisfy the following relation:

$$
\begin{gathered}
\frac{\Delta U_{i}}{\Delta I_{i}}=j \omega L+R_{A i C i}+j \omega L_{A i C i}+R_{\text {load }} \\
\frac{\Delta U_{c}}{\Delta I_{c}}=Z_{S}
\end{gathered}
$$

where, $I=1,2,3,4$, represents the feeder $\mathrm{F}_{1}-\mathrm{F}_{4} ;\left\{\Delta U_{i}, \Delta I_{i}\right\}$ represent the voltage fault component and the current fault component of the feeders at frequency $\omega ;\left\{\Delta U_{c}, \Delta I_{c}\right\}$ represent the voltage fault component and the current fault component of the converter at frequency $\omega ; R_{A k C k}, L_{A k C k}$ are equivalent resistances and inductances of the feeder $A_{k} C_{k}$, respectively. According to analysis above, the phase difference between the voltage fault component $\Delta U_{i}$ and current fault component $\Delta I_{i}$ of the normal feeders should be between $0 \sim 90^{\circ}$. In addition, the phase difference between the voltage fault component $\Delta U_{c}$ and current fault component $\Delta I_{c}$ of the converter should be between $0 \sim 90^{\circ}$.

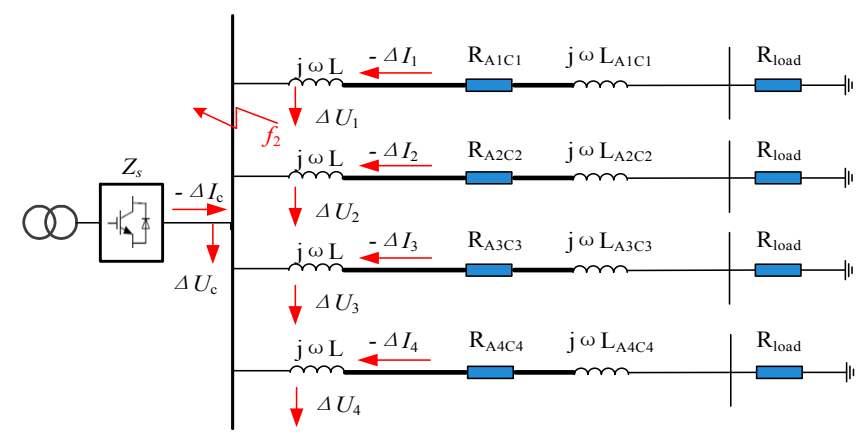

Figure 6. Frequency-domain fault superposition circuit for a pole-to-pole fault on the busbar.

\subsection{Analysis of Current Fault Component Characteristic Frequency Band}

It can be seen from the analysis above that the faulty feeder and faulty segment can be identified by the characteristics of the current fault component. However, the current fault component of DC feeder is a continuous spectrum signal. The low-frequency band of the signal is susceptible to DC load currents, while the high-frequency signal will be rapidly attenuated due to the fast rise of impedance of feeder in the case of high-frequency band. Therefore, in order to extract the characteristic frequency band of current fault component effectively and improve the sensitivity of the criteria, the amplitude-frequency characteristics of the current fault component will be analyzed. As shown in Figure 7, DC feeder $F_{1}$ in Figure 1 is modelled by a $\pi$-type equivalent circuit, and the frequency characteristics of MMC-MVDC distribution grid are analyzed as follows. 


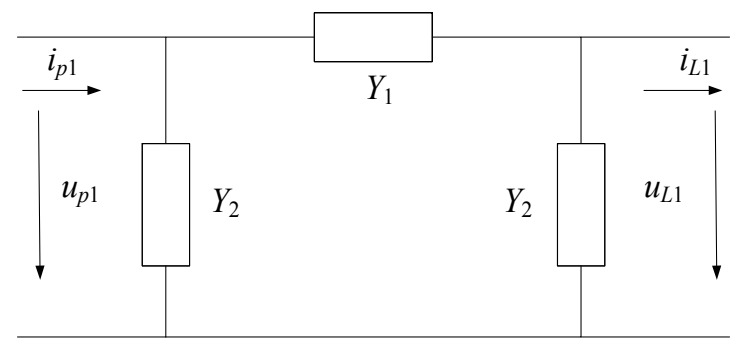

Figure 7. $\pi$-type equivalent circuit.

According to the two-port network equation, the current-voltage relation in Figure 7 can be expressed as:

$$
\left\{\begin{array}{l}
\dot{I}_{p 1}=\left(Y_{1}+Y_{2}\right) \dot{U}_{p 1}-Y_{1} \dot{U}_{L 1} \\
\dot{I}_{L 1}=Y_{1} \dot{U}_{p 1}-\left(Y_{1}+Y_{2}\right) \dot{U}_{L 1}
\end{array}\right.
$$

where, $\dot{I}_{p_{1}}$ and $\dot{U}_{p_{1}}$ denote the current and voltage at the beginning of $F_{1} . \dot{I}_{L 1}$ and $\dot{U}_{L 1}$ represent the current and voltage at the end of $F_{1} . Y_{1}$ and $Y_{2}$ are the admittance parameters of two-port network.

The transfer function between the current of beginning and end of the DC feeder is defined as follows:

$$
G(S)=\left.\frac{I_{L 1} \dot{(s)}}{I_{p 1} \dot{(}(s)}\right|_{U_{L 1}(s)=0}
$$

Substituting feeder parameters into Equation (8) and it can be given by:

$$
G(s)=\frac{Y_{1}}{Y_{2}+Y_{1}}=\frac{2}{C L l^{2} s^{2}+C R l^{2} s+2}
$$

where $R, L$ and $C$ denote the resistance, inductance and capacitance per unit length, respectively; $l$ represents the length of the feeder.

The standard form of oscillation links of transfer function can be expressed as:

$$
G^{*}(S)=\frac{1}{\left(s / \omega_{n}\right)^{2}+2 \varsigma\left(s / \omega_{n}\right)+1}
$$

The resonant angle frequency $\omega_{r}^{*}$ is given by:

$$
\omega_{r}^{*}=\omega_{n} \sqrt{1-2 \varsigma^{2}}
$$

Substitute Equation (9) into the form of Equation (10), $G(s)$ will be expressed as:

$$
\begin{gathered}
G(s)=\frac{1}{\left(s / \sqrt{2 / C L l^{2}}\right)^{2}+2(R l \sqrt{C / 8 L})\left(s / \sqrt{2 / C L l^{2}}\right)+1} \\
\omega_{n}=\sqrt{\frac{2}{C L l^{2}}}, \quad \zeta=\frac{R l}{2} \sqrt{\frac{C}{2 L}}
\end{gathered}
$$

Therefore, the resonant frequency $f_{r}$ can be calculated as:

$$
f_{r}=\omega_{r} / 2 \pi=\sqrt{\frac{2}{C L l^{2}}-\frac{R^{2}}{2 L^{2}}} / 2 \pi
$$


According to the line parameters shown in Table 1, the amplitude-frequency curves of the transfer function $G(s)$ can be obtained by substituting the different feeder lengths $l=20 \mathrm{~km}, 15 \mathrm{~km}$ and $10 \mathrm{~km}$ into Equation (12), respectively. The curves are shown in Figure 8.

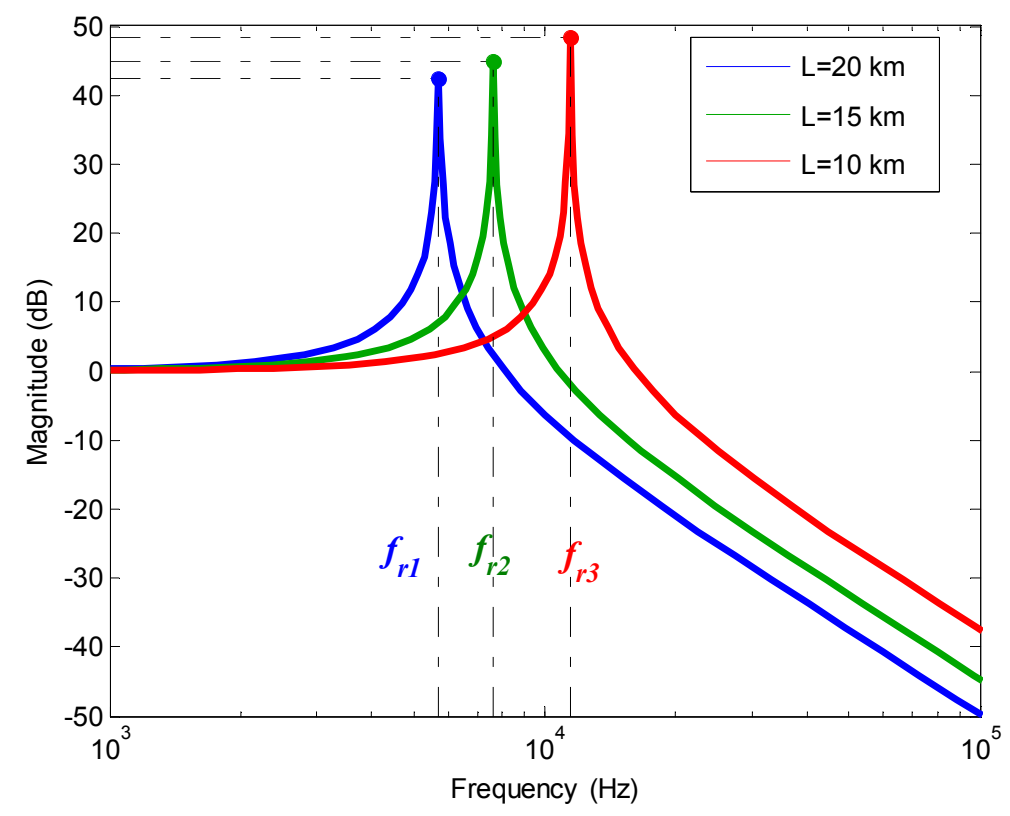

Figure 8. Amplitude-frequency characteristics of DC feeder.

According to Equation (14), the resonance frequencies $f_{r 1}=6054 \mathrm{~Hz}, f_{r 2}=8072 \mathrm{~Hz}$ and $f_{r 3}=12,107 \mathrm{~Hz}$ are obtained respectively. It can be seen from Figure 8 that for the same line length, the amplitude $\mathrm{A}(\omega)$ of the transfer function $G(s)$ is gradually increased from 1 in the low frequency band range $\left(0<f<f_{r}\right)$; When $f=f_{r}$, the amplitude reaches the resonance peak and the line has the least attenuation effect on the current fault component. For the high frequency band $\left(f>f_{r}\right),|\mathrm{A}(\omega)|$ decays rapidly from the resonant peak. When the length of the feeder reaches maximum length of $20 \mathrm{~km}, \omega_{r}$ reaches a minimum value of $6054 \mathrm{~Hz}$. As the frequency increases from $6054 \mathrm{~Hz}$, the attenuation effect on the current fault component will become stronger. In order to reduce the attenuation of the circuit, the frequency should not be greater than $6054 \mathrm{~Hz}$. Meanwhile, as most of AC distributed power works in $50 \mathrm{~Hz}$ and most of DC distributed power works in low-frequency band, the low-frequency band of the fault component is easily affected by the load current and distributed power. Therefore, this paper selects characteristic frequency band between $500 \mathrm{~Hz}$ and $4000 \mathrm{~Hz}$ for analysis.

\section{Application of S-Transform}

S-transform has excellent time-frequency resolution characteristics. The height and width of Gaussian window changes with the variation of frequency. Based on good frequency resolution in the low frequency part and good time resolution in the high frequency part [25], it is very easy to extract the characteristic frequency band of current fault component using S-transform.

\subsection{The S-Transform Theory}

$\mathrm{S}$ transform is the development of wavelet transform and short-time Fourier transform [26], the $\mathrm{S}$ transform of a signal $x(t)$ can be expressed as:

$$
S(\tau, f)=\int_{-\infty}^{+\infty} x(t) \omega(\tau-t, f) e^{-i 2 \pi f \tau} d t
$$


where, $f$ and $\tau$ are the frequency-shift factor and time-shift factor; $\omega(\tau-t, f)$ is Gaussian window function which can be defined as:

$$
\omega(\tau-t, f)=\frac{|f|}{\sqrt{2 \pi}} e^{-\frac{(\tau-t)^{2} f^{2}}{2}}
$$

The $\mathrm{S}$ transform of a discrete signal $x[k T]$ can be realized by the fast Fourier transform (letting $f \rightarrow n / N T$ and $\tau \rightarrow j T)$ :

$$
\left\{\begin{array}{l}
S\left[j T, \frac{n}{M T}\right]=\sum_{m=0}^{M-1} X\left[\frac{m+n}{M T}\right] e^{-\frac{2 \pi^{2} m^{2}}{n^{2}}} e^{\frac{i 2 \pi m j}{M}}, n \neq 0 \\
S[j T, 0]=\frac{1}{M} \sum_{m=0}^{M-1} x\left[\frac{m}{M T}\right], n=0
\end{array}\right.
$$

where $k, j, m$ and $n \in(0, M-1) . T$ is the sampling interval and $M$ is the sampling number. $X[n / N T]$ denotes the discrete Fourier transform of $x[j T]$ and $e^{-2 \pi^{2} m^{2} / n^{2}}$ represents the Fourier spectrum of Gaussian window function.

\subsection{S transform Characteristic Frequency Band (STCFB)}

The $\mathrm{S}$ matrix obtained by $\mathrm{S}$ transform can be defined as $S_{a}[p, q]$, where $q$ is a column vector representing the amplitude-frequency characteristics of the signal at a sampling point, $p$ is a row vector representing the time-domain characteristics of the signal at a certain frequency. Then STCFB of a signal at a certain time $q$ can be defined as:

$$
S[q]=\sum_{p=500}^{p=4000} S[p, q]
$$

where $q=1,2 \ldots M$. STCFB waveform can be drawn by calculating $S[q]$ at each sampling point.

\subsection{Analysis of STCFB Phase}

In the matrix $S_{A}[p, q]$, each element represents both of amplitude information and phase information of the signal at a particular frequency at a particular sampling point. The phase information extracted by single frequency has insufficient reliability and is also susceptible to interference signals. According to the analysis of the characteristic frequency band in the previous section, the STCFB Phase transformed from the signal $\mathrm{S}$ can be extracted as:

$$
S_{A}[q]=\operatorname{angle}(S[q])
$$

where, $S_{A}[q]$ is the phase of $S[q]$, utilized to identify the faulty feeders and locate the faulty segments.

\section{Protection and Location Scheme Based on S-Transform}

\subsection{Protection Starting Criterion}

When MMC-MVDC system is in normal operation, the current fault component at the protection installation of DC distribution grid is almost zero. While the pole-to-pole fault occurs, the short circuit current at the protection installation of the line will rise rapidly. The current gradient is utilized to detect the abnormality since the system abnormality can be characterized by a current change [27], which can be expressed as:

$$
\nabla I(k)=\frac{1}{3} \sum_{i=0}^{2} I(k-i)-\frac{1}{3} \sum_{i=3}^{5} I(k-i)
$$


where, $I(k-i)$ is the $i$-th sampling current value prior to the present moment; $\nabla I(k)$ is the calculated current gradient.

The start criterion of the protection is defined as:

$$
\nabla I(k)>\Delta_{1}
$$

where, $\Delta_{1}$ is the starting threshold value. The value is greater than the maximum value of the current gradient during normal operation and switching load. According to the analysis and large simulations, $\Delta_{1}=5 \mathrm{~A}$ is obtained.

\subsection{Protection Criterion on the Busbar and Feeders}

According to the analysis above, it can be seen that in the characteristic frequency band, both the forward and backward impedance of the protection can be considered to be inductive. Therefore, after the protection starts, the busbar fault and feeder fault can be determined according to the STCFB Phase of voltage fault component and current fault component of feeders and the converter. When the protection starts, STCFB Phase difference of the voltage fault component and current fault component of feeders and the converter can be calculated based on the averaging method.

$$
\begin{aligned}
\Delta S_{A i} & =\frac{1}{M} \sum_{q=1}^{M}\left|S_{A U i}(q)-S_{A I i}(q)\right| \\
\Delta S_{A c} & =\frac{1}{M} \sum_{q=1}^{M}\left|S_{A U c}(q)-S_{A I c}(q)\right|
\end{aligned}
$$

where, $i=1,2,3,4$, denotes four feeders; $S_{A U i}(q)$ and $S_{A I i}(q)$ are STCFB Phase of voltage fault component and current fault component at the $q$-th sampling point of the $i$-th feeder, respectively; $S_{A U_{C}}(q)$ and $S_{A I C}(q)$ are STCFB Phase of voltage fault component and current fault component at the $q$-th sampling point of the converter; $M$ is the number of sampling points in the data window. Theoretically, when the feeder $i$ is a faulty feeder, the STCFB Phase difference between the two signals should be between $180^{\circ}$ and $270^{\circ}$; On the other hand, when the feeder $i$ is a normal feeder, the STCFB Phase difference between the two signals should be between $0^{\circ} \sim 90^{\circ}$. Considering the sensitivity and selectivity comprehensively, the criteria for identifying the faulty feeder can be constructed as follows:

$$
160^{\circ}<\Delta S_{A i}<290^{\circ}
$$

If Equation (24) is satisfied, the feeder $i$ can be determined as faulty feeder.

The criterion for identifying the faulty busbar can be constructed as follows:

$$
\left\{\begin{array}{l}
-20^{\circ}<\Delta S_{A i}<110^{\circ}, i=1,2,3,4 \\
-20^{\circ}<\Delta S_{A c}<110^{\circ}
\end{array}\right.
$$

If $\Delta S_{A i}$ and $\Delta S_{A c}$ satisfy the criterion in Equation (25), the pole-to-pole fault can be determined on the DC busbar.

\subsection{Faulty Segment Location Criterion}

On the basis of the characteristic analysis in Section 2.3, when an internal fault occurs on the segment, the STCFB Phase of current fault component on both sides of the segment are approximately 
the same; while the segment is faulty, the STCFB Phase on both sides of the segment are approximately opposite. Defining $\Delta S_{A l}$ as STCFB Phase difference of different feeder segments, then:

$$
\Delta S_{A l}=\frac{1}{M} \sum_{q=1}^{M}\left|S_{A I l}(q)-S_{A I r}(q)\right|
$$

where, $S_{\text {AII }}(q)$ and $S_{A I r}(q)$ are the STCFB Phase of the current fault component at the $q$-th sampling point on both sides of the segment. The faulty segment location criterion can be constructed as follows:

$$
-30^{\circ}<\Delta S_{A l}<30^{\circ}
$$

When Equation (27) is satisfied, the faulty segment is determined. Otherwise, it is judged as a normal segment.

\subsection{Flow Chart of Protection and Location Scheme}

Based on the analysis above, the flow chart of protection and segment location scheme shown in Figure 9 can be designed based on the protection starting criterion, feeders and busbar protection criterion, and segment location criterion.

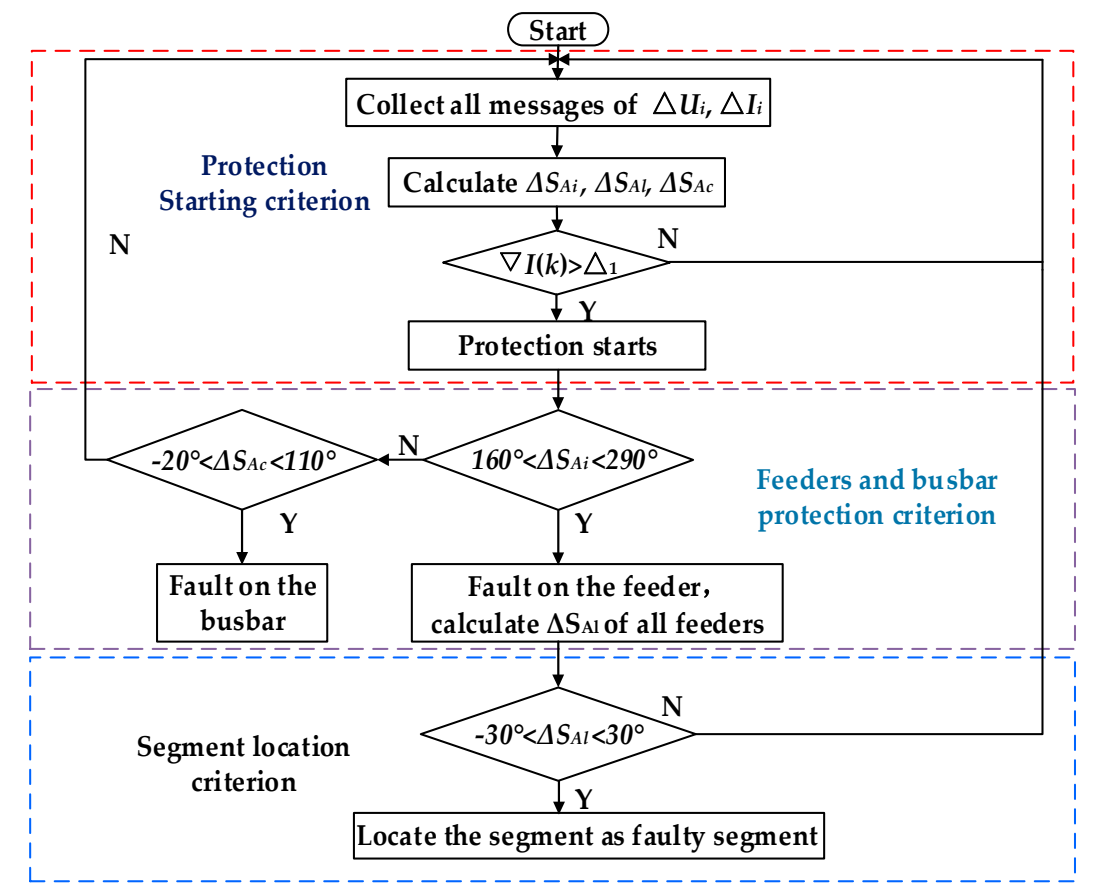

Figure 9. Flow chart of protection and location scheme for pole-to-pole fault.

\section{Simulation and Analysis}

In order to validate the proposed protection and location criteria, $\mathrm{a} \pm 10 \mathrm{kV}$ natural bipolar radial MMC-MVDC simulation model was built in Figure 1. The pole-to-pole faults are set at different fault locations to test the reliability of the method. The protection units $\left(R_{11}, R_{12}, R_{13}, R_{14}, R_{21}, R_{22}, R_{23}\right.$, $R_{24}, R_{31}, R_{32}, R_{33}, R_{34}, R_{41}, R_{42}, R_{43}, R_{44}$, and $R_{1}$ ) are located as shown in the figure. The entire data window is $2 \mathrm{~ms}$ in length and the sampling frequency is $25 \mathrm{kHz}$. 


\subsection{Metallic Pole-to-Pole Fault}

Setting a metallic pole-to-pole fault at $f_{1}$ in the middle of segment $\mathrm{B}_{1} \mathrm{C}_{1}$, the STCFB Phase of current and voltage fault component of all feeders are shown in Figure 10. The results are indicated in Table 3.
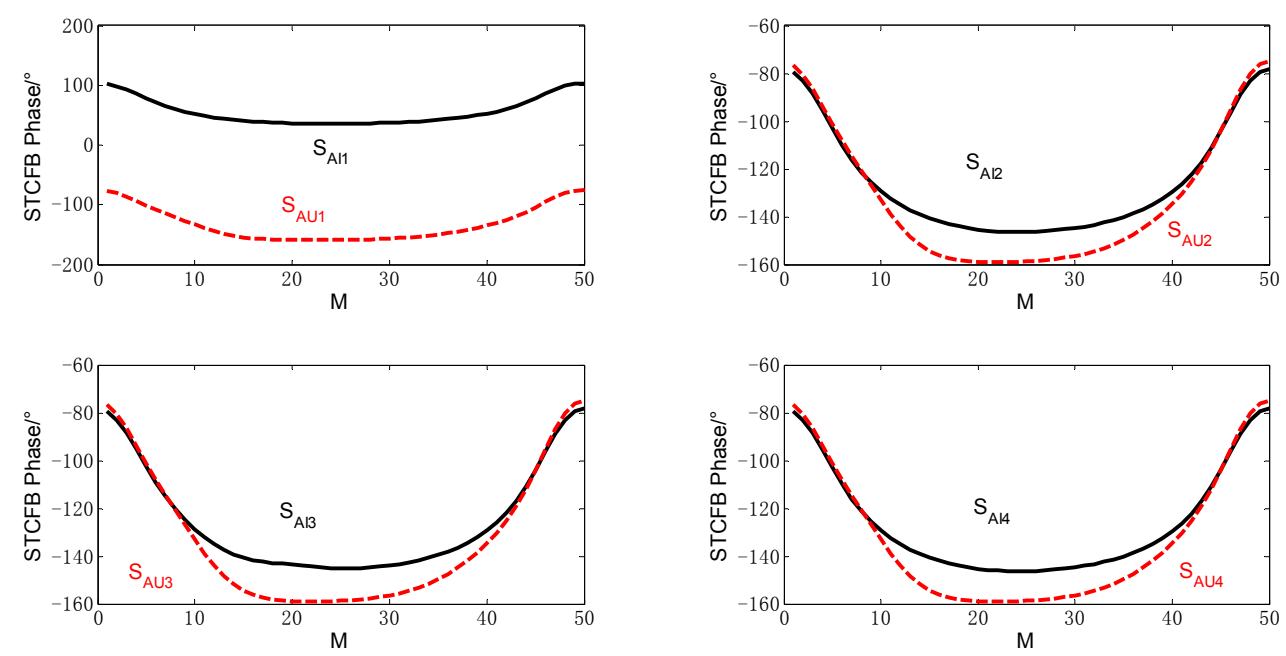

Figure 10. S-transform characteristic frequency band (STCFB) Phase of faulty feeder under pole-to-pole fault.

Table 3. Simulation results of STCFB (S-transform characteristic frequency band) Phase difference for the fault at $f_{1}$.

\begin{tabular}{|c|c|c|c|c|}
\hline \multicolumn{4}{|c|}{$\Delta S_{A i}\left({ }^{\circ}\right)$} & \multirow{2}{*}{ Simulation Results } \\
\hline$F_{1}$ & $F_{2}$ & $F_{3}$ & $F_{4}$ & \\
\hline 188.461 & 6.435 & 7.055 & 6.492 & Fault on $\mathrm{F}_{1}$ \\
\hline
\end{tabular}

Where, $\left\{S_{A U i}, S_{A I i}\right\}$ represents the STCFB Phase of voltage fault component and current fault component of feeder $\mathrm{F}_{1}-\mathrm{F}_{4} . \Delta S_{A i}$ is the phase difference of voltage fault component and current fault component of all feeders. According to Figure 10 and Table 3, the STCFB Phase difference of voltage fault component and current fault component on the head of $F_{1}$ is $188.461^{\circ}$. While the STCFB Phase difference of voltage fault component and current fault component on the head of $\mathrm{F}_{2}, \mathrm{~F}_{3}$, and $\mathrm{F} 4$ are $6.435^{\circ}, 7.055^{\circ}, 6.492^{\circ}$. Thus, $\mathrm{F}_{1}$ can be determined as the faulty feeder.

Further analyzing STCFB Phase on both sides of segment $A_{1} B_{1}$ and $B_{1} C_{1}$, the waveforms are shown in Figure 11 and the simulation results are indicated in Table 4.
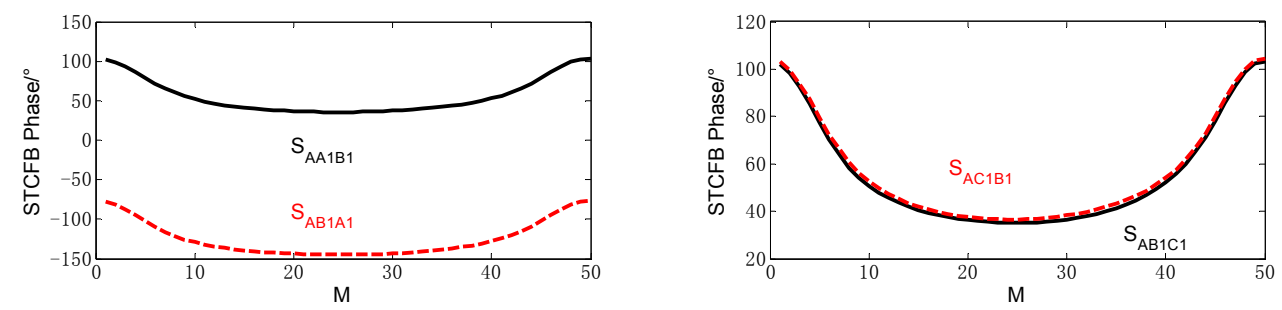

Figure 11. STCFB Phase on both sides of segment $A_{1} B_{1}$ and $B_{1} C_{1}$. 
Table 4. Simulation results of STCFB Phase difference for the segment $A_{1} B_{1}$ and $B_{1} C_{1}$.

\begin{tabular}{cccc}
\hline \multicolumn{3}{c}{$\Delta S_{A l}\left(^{\circ}\right)$} & Simulation Results \\
\cline { 1 - 2 } $\mathbf{A}_{\mathbf{1}} \mathbf{B}_{\mathbf{1}}$ & $\mathbf{B}_{\mathbf{1}} \mathbf{C}_{\mathbf{1}}$ & \\
\hline 180.723 & 1.671 & Fault on $\mathrm{B}_{1} \mathrm{C}_{1}$ \\
\hline
\end{tabular}

Where, $\left\{S_{A A 1 B 1}, S_{A B 1 A 1}\right\},\left\{S_{A B 1 C 1}, S_{A C 1 B 1}\right\}$ represent the STCFB Phase on both sides of segment $\mathrm{A}_{1} \mathrm{~B}_{1}$ and $\mathrm{B}_{1} \mathrm{C}_{1} ; \Delta S_{A l}$ is the STCFB Phase difference on both sides of segment $\mathrm{A}_{1} \mathrm{~B}_{1}$ and $\mathrm{B}_{1} \mathrm{C}_{1}$. As shown in Figure 11 and Table 4, the STCFB Phase difference of voltage fault component and current fault component on both sides of $A_{1} B_{1}$ is $180.723^{\circ}$. While the STCFB Phase difference of voltage fault component and current fault component on both sides of $B_{1} C_{1}$ is $1.671^{\circ}$. Thus, $B_{1} C_{1}$ can be identified as the faulty segment.

\subsection{Metallic Bus Fault}

A metallic fault is set at $f_{2}$ on the busbar as shown in Figure 1 . At this time, $\nabla I(k)$ is $25 \mathrm{~A}$, and the protection starts. The STCFB Phase of voltage fault component and current fault component for four feeders are shown in Figure 12. The simulation results are indicated in Table 5.
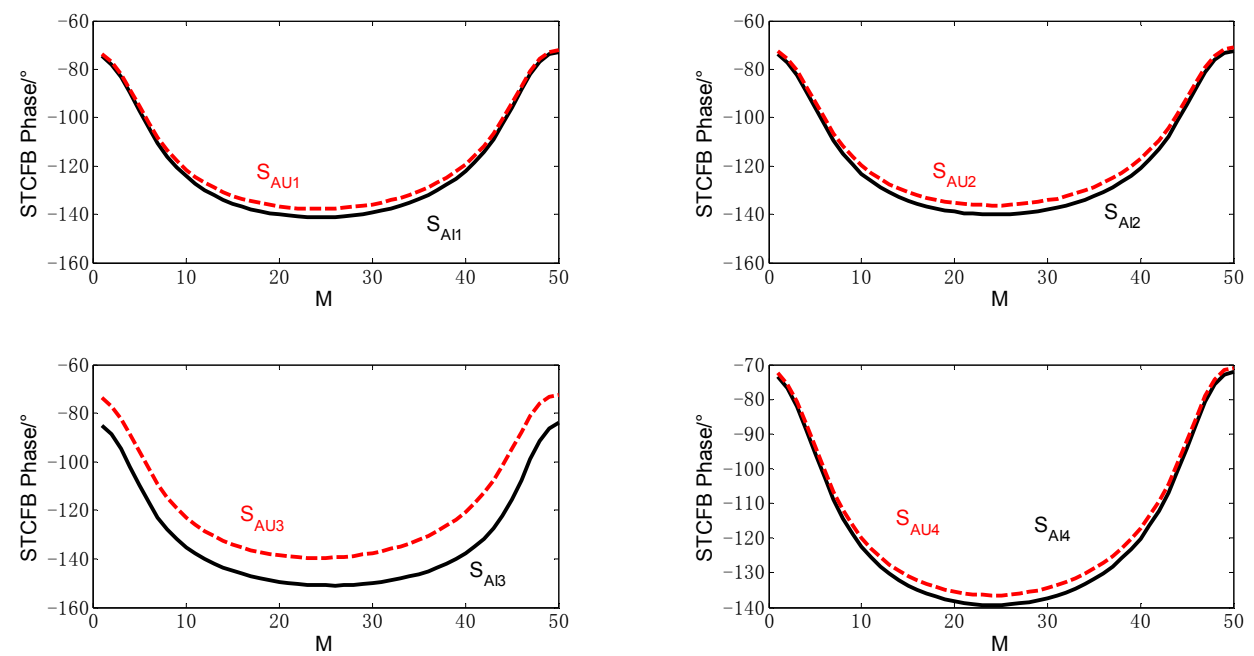

Figure 12. STCFB Phase on both sides of segment $A_{1} B_{1}$ and $B_{1} C_{1}$.

Table 5. Simulation results of fault on the busbar.

\begin{tabular}{|c|c|c|c|c|c|}
\hline \multirow{2}{*}{$\Delta S_{A c}\left(^{\circ}\right)$} & \multicolumn{4}{|c|}{$\Delta S_{A i}\left({ }^{\circ}\right)$} & \multirow{2}{*}{ Simulation Results } \\
\hline & $F_{1}$ & $F_{2}$ & $F_{3}$ & $F_{4}$ & \\
\hline 25.613 & 2.647 & 3.258 & 13.495 & 2.480 & Fault on $f_{2}$ \\
\hline
\end{tabular}

According to Figure 12 and Table 5, the STCFB Phase difference of voltage fault component and current fault component at the head of $\mathrm{F}_{1}, \mathrm{~F}_{2}, \mathrm{~F}_{3}, \mathrm{~F}_{4}$ is $2.647^{\circ}, 3.258^{\circ}, 13.495^{\circ}$, and $2.480^{\circ}$. The STCFB Phase difference of voltage fault component and current fault component of the converter is $25.613^{\circ}$. Therefore, the fault is determined on the busbar.

\subsection{Simulation for Influencing Factors}

In order to verify the reliability of the proposed protection and location criterion under different factors, extensive simulations were performed as follows. 
(1) Fault on the feeder under different fault resistances: Faults under different resistances are set at $f_{1}$ in the middle of segment $B_{1} C_{1}$. The simulation results of feeders are indicated in Table 6 . The results of segments are indicated in Table 7.

Table 6. Simulation results of faulty feeders under different fault resistances.

\begin{tabular}{|c|c|c|c|c|c|}
\hline \multirow{2}{*}{ Resistance/ $\Omega$} & \multicolumn{4}{|c|}{$\Delta S_{A i}\left({ }^{\circ}\right)$} & \multirow{2}{*}{ Simulation Results } \\
\hline & $\mathbf{F}_{1}$ & $F_{2}$ & $F_{3}$ & $\mathbf{F}_{4}$ & \\
\hline 20 & 189.713 & 7.124 & 7.253 & 7.053 & Fault on $\mathrm{F}_{1}$ \\
\hline 50 & 190.541 & 7.521 & 8.552 & 7.535 & Fault on $\mathrm{F}_{1}$ \\
\hline
\end{tabular}

Table 7. Simulation results of faulty segments under different fault resistances.

\begin{tabular}{|c|c|c|c|}
\hline \multirow{2}{*}{ Resistance $/ \Omega$} & \multicolumn{2}{|c|}{$\Delta S_{A l}\left({ }^{\circ}\right)$} & \multirow{2}{*}{ Simulation Results } \\
\hline & $\mathbf{A}_{1} \mathbf{B}_{1}$ & $B_{1} C_{1}$ & \\
\hline 20 & 182.194 & 7.405 & Fault on $B_{1} C_{1}$ \\
\hline 50 & 183.052 & 7.704 & Fault on $B_{1} C_{1}$ \\
\hline
\end{tabular}

On the basis of Tables 6 and 7, $F_{1}$ can be selected as faulty feeder under different resistances. In addition, segment $\mathrm{B}_{1} \mathrm{C}_{1}$ can be correctly located.

(2) Simulation of fault on the busbar under different fault resistances:

Faults with different transition resistances are set at $f_{2}$ on the busbar. The identification results are shown in Table 8.

Table 8. Simulation results of faulty busbar under different fault resistances.

\begin{tabular}{ccccccl}
\hline \multirow{2}{*}{ Resistance $/ \Omega$} & \multirow{2}{*}{$\Delta \boldsymbol{S}_{A c}\left({ }^{\circ}\right)$} & \multicolumn{4}{c}{$\Delta \boldsymbol{S}_{A i}\left(^{\circ}\right)$} & \multirow{2}{*}{ Simulation Results } \\
\cline { 3 - 6 } & & $\mathbf{F}_{\mathbf{1}}$ & $\mathbf{F}_{\mathbf{2}}$ & $\mathbf{F}_{\mathbf{3}}$ & $\mathbf{F}_{\mathbf{4}}$ & \\
\hline 20 & 22.124 & 1.672 & 9.860 & 16.178 & 21.799 & Fault on busbar \\
50 & 20.118 & 1.276 & 7.986 & 12.552 & 19.637 & Fault on busbar \\
\hline
\end{tabular}

As the results shown in Table 8, the fault on the busbar can be correctly determined under different resistances. The results show that the resistance has little impact on the criteria.

(3) Simulation of different fault locations: Set the pole-to-pole fault at $\mathrm{f}_{3}$ and take the transition resistance as $20 \Omega$. The simulation results of STCFB Phase difference on both sides of segment $A_{2} B_{2}$ and $B_{2} C_{2}$ are shown in Figure 13. The abscissa indicates the distance from the fault point to $\mathrm{A}_{2}$.
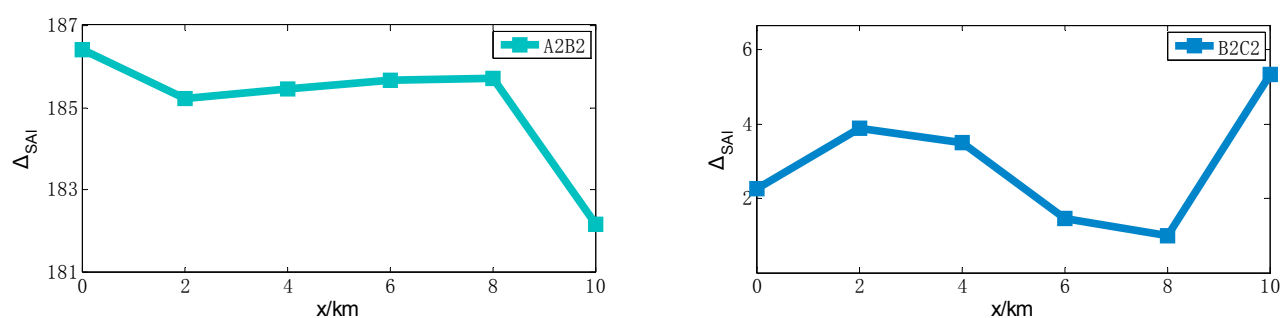

Figure 13. STCFB Phase of faults on different locations in the segment $A_{2} B_{2}$ and $B_{2} C_{2}$. 
According to Figure 13, when the fault occurs on different locations of the segment, the faulty segment can be correctly located, and the sensitivity is high.

(4) Noise: The noise interferences will be doped in the voltage and current fault component, which will easily cause maloperation of protection. Therefore, Gaussian white noise with different decibels is added to the voltage and current fault component signals. The simulation results are shown in Table 9.

Table 9. Simulation results of feeder under different Gaussian noise.

\begin{tabular}{cccccc}
\hline \multirow{2}{*}{ Gaussian Noise/dB } & \multicolumn{4}{c}{$\Delta \boldsymbol{S}_{\boldsymbol{A i}}\left(^{\circ}\right)$} & \multirow{2}{*}{ Simulation Results } \\
\cline { 2 - 5 } & $\mathbf{F}_{\mathbf{1}}$ & $\mathbf{F}_{\mathbf{2}}$ & $\mathbf{F}_{\mathbf{3}}$ & $\mathbf{F}_{\mathbf{4}}$ & \\
\hline 30 & 188.697 & 7.505 & 9.208 & 7.532 & Fault on $\mathrm{F}_{1}$ \\
40 & 188.758 & 6.695 & 6.901 & 6.368 & Fault on $\mathrm{F}_{1}$ \\
80 & 188.458 & 6.437 & 7.050 & 6.487 & Fault on $\mathrm{F}_{1}$ \\
\hline
\end{tabular}

On the basis of the simulation results above, it can be seen that the scheme is hardly affected by noise.

(5) Fault on AC side: Different types of pole-to-pole faults are set at $f_{4}$ on the AC busbar. According to the simulation, during the entire transient process, $\nabla I(k)<\Delta_{1}$ is always satisfied. Therefore, the protection does not start, and the system can still operate normally.

\section{Conclusions}

Due to the existing protection and location scheme mainly focus on HVDC grid and LVDC grid, a novel protection and location method was firstly proposed for MMC-MVDC grid. Considering the transient characteristics of MMC-MVDC distribution grids, the scheme can be divided into three stages, namely: (1) Protection starting criterion; (2) feeders and busbar protection criterion, and (3) segment location criterion. Utilizing PSCAD/EMTDC software, a radial MMC-MVDC distribution grid was constructed and extensive simulations were realized. From the theoretical analysis and simulation results, the following conclusions could be drawn:

(1) The simulation results show that influencing factors such as the fault resistance, the noises and fault position, can hardly affect the correct operation of the proposed criteria.

(2) Utilizing the non-unit data and the data window of $2 \mathrm{~ms}$ to protect the feeder and the busbar, the protection is fast and reliable.

(3) The criteria only utilizes the current and voltage fault component to protect the system and locate the fault, which is adaptable in the intricate topologies.

Author Contributions: This paper was a collaborative effort between the authors. All authors read and approved the final manuscript. The individual contribution can be stated as follows. Data curation, G.Z.; Formal analysis, X.W.; Methodology, Y.Z.; Resources, C.S.; Software, L.J.; Supervision, G.Z.

Acknowledgments: The authors gratefully acknowledge the National Natural Science Foundation of China (51677109), and the Science and Technology Project of State Grid Corporation of China (5204BB1600CS).

Conflicts of Interest: The authors declare no conflict of interest.

\section{References}

1. Bukhari, S.; Zaman, M.; Haider, R.; Oh, Y.; Kim, C. A protection scheme for microgrid with multiple distributed generations using superimposed reactive energy. Int. J. Electr. Power Energy Syst. 2017, 92, 156-166. [CrossRef] 
2. Li, X.; Cui, X.; Lu, T.; Wang, D.; Ma, W.; Bian, X. Comparison between the audible noises generated from single corona source under DC and AC corona discharge. CSEE JPES 2015, 1, 23-30.

3. Techakittiroj, K.; Wongpaibool, V. Co-existance between AC-Distribution and DC-Distribution: In the View of Appliances. Available online: http:/ / repository.au.edu/bitstream/handle/6623004553/17921/ProceedingPaper-Abstract-17921.PDF?sequence=2\&isAllowed =y (accessed on 8 August 2018).

4. Xue, S.; Gao, F.; Sun, W.; Li, B. Protection Principle for a DC Distribution System with a Resistive Superconductive Fault Current Limiter. Energies 2015, 8, 4839-4852. [CrossRef]

5. Mehrasa, M.; Pouresmaeil, E.; Zabihi, S.; Caballero, J.C.T.; Catalão, J.P.S. A Novel Modulation Function-Based Control of Modular Multilevel Converters for High Voltage Direct Current Transmission Systems. Energies 2016, 9, 867. [CrossRef]

6. Mehrasa, M.; Pouresmaeil, E.; Zabihi, S; Vechiu, I.; Catalão, J.P.S. A multi-loop control technique for the stable operation of modular multilevel converters in HVDC transmission systems. Int. J. Electr. Power Energy Syst. 2018, 96, 194-207. [CrossRef]

7. Mehrasa, M.; Pouresmaeil, E.; Zabihi, S.; Catalão, J.P.S. Dynamic Model, Control and Stability Analysis of MMC in HVDC Transmission Systems. IEEE Trans. Power Deliv. 2017, 32, 1471-1482. [CrossRef]

8. Mehrasa, M.; Pouresmaeil, E.; Taheri, S.; Vechiu, I.; Catalão, J.P.S. Novel Control Strategy for Modular Multilevel Converters Based on Differential Flatness Theory. IEEE J. Emerg. Sel. Top. Power Electron. 2018, 6, 888-897. [CrossRef]

9. Sun, G.; Shi, B.; Zhao, Y.; Li, S. Research on the fault location method and protection configuration strategy of MMC based DC distribution grid. Power Syst. Prot. Control 2015, 43, 127-133.

10. Xue, S.M.; Liu, C. Line-to-Line Fault Analysis and Location in a VSC-Based Low-Voltage DC Distribution Network. Energies 2018, 11, 536. [CrossRef]

11. Jamali, S.Z.; Bukhari, S.B.A.; Khan, M.O.; Mehdi, M.; Noh, C.H.; Gwon, G.H.; Kim, C.H. Protection Scheme of a Last Mile Active LVDC Distribution Network with Reclosing Option. Energies 2018, 11, 1093. [CrossRef]

12. Chaudhuri, N.R.; Chaudhuri, B.; Majumder, R.; Yazdani, A. Multi-Terminal Direct-Current Grids: Modeling, Analysis, and Control; Wiley-IEEE Press: Hoboken, NJ, USA, 2014.

13. Mehrasa, M.; Pouresmaeil, E.; Akorede, M.F.; Zabihi, S.; Catalão, J.P.S. Function-based modulation control for modular multilevel converters under varying loading and parameters conditions. IET Gener. Transm. Distrib. 2017, 11, 3222-3230. [CrossRef]

14. Azizi, S.; Afsharnia, S.; Sanaye-Pasand, M. Fault location on multi-terminal DC systems using synchronized current measurements. Int. J. Electr. Power Energy Syst. 2014, 63, 779-786. [CrossRef]

15. Zhang, S.; Zou, G.B.; Huang, Q.; Gao, H. A Traveling-Wave-Based Fault Location Scheme for MMC-Based Multi-Terminal DC Grids. Energies 2018, 11, 401. [CrossRef]

16. Leterme, W.; Beerten, J.; Hertem, D.V. Nonunit Protection of HVDC Grids with Inductive DC Cable Termination. IEEE Trans. Power Deliv. 2016, 31, 820-828. [CrossRef]

17. Baran, M.E.; Mahajan, N.R. Overcurrent Protection on Voltage-Source-Converter-Based Multi-terminal DC Distribution Systems. IEEE Trans. Power Deliv. 2007, 22, 406-412. [CrossRef]

18. Xue, S.M.; Chen, C.C.; Yi, J.; Li, B.; Wang, Y. Protection for DC Distribution System with Distributed Generator. J. Appl. Math. 2014, 2014, 1-12. [CrossRef]

19. Feng, X.; Li, Q.; Pan, J. A novel fault location method and algorithm for DC distribution protection. IEEE Trans. Ind. Appl. 2017, 53, 1834-1840. [CrossRef]

20. Tang, L.; Ooi, B.T. Locating and Isolating DC Faults in Multi-Terminal DC Systems. IEEE Trans. Power Deliv. 2007, 22, 1877-1884. [CrossRef]

21. Zheng, X.; Tai, N.; Wu, Z.; Thorp, J. Harmonic current protection scheme for voltage source converter-based high-voltage direct current transmission system. IET Gener. Transm. Distrib. 2018, 8, 1509-1515. [CrossRef]

22. Yang, J.; Fletcher, J.E.; O'Reilly, J. Multi terminal DC Wind Farm Collection Grid Internal Fault Analysis and Protection Design. IEEE Trans. Power Deliv. 2010, 25, 2308-2318. [CrossRef]

23. Sneath, J.; Rajapakse, A.D. Fault Detection and Interruption in an Earthed HVDC Grid Using ROCOV and Hybrid DC Breakers. IEEE Trans. Power Deliv. 2016, 31, 973-981. [CrossRef]

24. Song, G.B.; Luo, J.; Gao, S.P.; Wang, X.; Tassawar, K. Detection method for single-pole-grounded faulty feeder based on parameter identification in MVDC distribution grids. Int. J. Electr. Power Energy Syst. 2018, 97, 85-92. [CrossRef] 
25. Zhao, P.; Chen, Q.; Sun, K.; Xi, C. A Current Frequency Component-Based Fault-Location Method for Voltage-Source Converter-Based High-Voltage Direct Current (VSC-HVDC) Cables Using the S Transform. Energies 2017, 10, 1115. [CrossRef]

26. Stockwell, R.G.; Mansinha, L.; Lowe, R.P. Localization of the complex spectrum: the S transform. IEEE Trans. Signal Process. 1996, 44, 998-1001. [CrossRef]

27. Kong, F.; Hao, Z.; Zhang, S.; Zhang, B. Development of a Novel Protection Device for Bipolar HVDC Transmission Lines. IEEE Trans. Power Deliv. 2014, 29, 227-2278. [CrossRef] 